\title{
The perception of some personality traits in female voice
}

\author{
Glenda Gurrado \\ Department of Letters, Languages and Arts, University of Bari, Italy \\ https://doi.org/10.36505/ExLing-2018/09/0010/000343
}

\begin{abstract}
The ethological model called the Frequency Code developed by Ohala (1983, 1984) postulates a correlation between pitch and the expression of power: low-pitched voices communicate a meaning of dominance while high-pitched voices transmit a meaning of submission. Based on this awareness, the present research aims to investigate the relationship between the pitch variation of female voice and some specific personality markers, in particular we tested the perception of dominance.

Key words: Frequency Code, female voice, pitch, dominance/submissiveness dimension, Visual Analogue Scale
\end{abstract}

\section{Introduction}

According to the Frequency Code, fundamental frequency is an instrument of transmission of emotions. In particular John Ohala (1983, 1984) argues that some 'social messages' can be communicated by means of $\mathrm{f} 0$ : both in animals and in humans low values of $\mathrm{f} 0$ convey a sense of dominance, confidence and aggressiveness whereas high values of $\mathrm{f0}$ transmit a meaning of submission and vulnerability. In humans the scenario is more complex because pitch influences the prosodic structure of the entire sentence. Furthermore the sexual dimorphism of the vocal anatomy of men and women plays a key role in favour of the innate character of the Frequency Code. Indeed, as is widely known, there is a correlation between the size of the vocal folds and the pitch of voice: small vocal folds, typically those of female, produce high frequencies, on the contrary, large vocal folds, typically those of adult male, produce low frequencies. This is an important aspect that contributes to differentiating the role of women and men in society and in everyday life.

\section{Methodology}

To date the female voice has often been analysed with reference to the male voice. For this reason this study aims to verify the role played by pitch variation and other prosodic aspects of female voice in the listeners' perception of dominance. The hypothesis is that lower f0 values make a voice sound more dominant, on the contrary, higher f0 values make a voice sound more subordinate. The participants are three

ExLing 2018: Proceedings of $9^{\text {th }}$ Tutorial and Research Workshop on Experimental Linguistics, 28-30 August, Paris, Frannce 
female speakers of Bari Italian ranging from age 22 to 25 . We selected a low-pitched voice (RV), a medium-pitched voice (GM) and a highpitched voice $(\mathrm{CI})^{1}$. The speakers were asked to read an article (read speech) and to describe a cooking recipe (spontaneous speech). They were recorded by means of a digital recorder (WAV. format, $44100 \mathrm{~Hz}$, 32 bit).

A perceptive analysis was conducted in order to test the way listeners judge the speakers' personality. A group of 50 Italian listeners $(36 \mathrm{~F}$ and $14 \mathrm{M}$, average age 23.8 years) was invited to evaluate the three voices by means of five pairs of adjectives: small/large, submitted/dominant, lacking confidence/confident, vulnerable/aggressive, desirous of goodwill/secure. The listeners had to mark their judgments on a Visual Analogue Scale (VAS), (Chen et al. 2004) ${ }^{2}$. We divided the VAS in 10 parts and placed two opposite adjectives on the two ends of the line. It was predicted that listeners would evaluate the low-pitched voice (RV) as dominant by marking the slash on the right side of the VAS; on the contrary, we supposed that the high-pitched voice (CI) would be judged as submissive by being associated with the left side of the scale.

\section{Results and discussion}

The data collected so far does not show a precise predictive tendency (see Table 1.).

Table 1. Medium values (over) and standard deviation (under) of the auditory judgments made by listeners by means of five pairs of adjectives with reference to read (R) and spontaneous (Sp) speech.

\begin{tabular}{|l|l|l|l|l|l|l|l|l|l|l|l|l|l|l|}
\hline \hline & \multicolumn{2}{|l|}{ Small/Large } & \multicolumn{2}{l}{$\begin{array}{l}\text { Lacking } \\
\text { confidence/ } \\
\text { Confident }\end{array}$} & \multicolumn{2}{l}{$\begin{array}{l}\text { Submissive/ } \\
\text { Dominant }\end{array}$} & \multicolumn{2}{l|}{$\begin{array}{l}\text { Vulnerable/ } \\
\text { Aggressive }\end{array}$} & \multicolumn{2}{l}{$\begin{array}{l}\text { Desirous of } \\
\text { Goodwill/ } \\
\text { Secure }\end{array}$} & \multicolumn{2}{l}{$\begin{array}{l}\text { Medium } \\
\text { values }\end{array}$} \\
\hline & $\mathrm{R}$ & $\mathrm{Sp}$ & $\mathrm{R}$ & $\mathrm{Sp}$ & $\mathrm{R}$ & $\mathrm{Sp}$ & $\mathrm{R}$ & $\mathrm{Sp}$ & $\mathrm{R}$ & $\mathrm{Sp}$ & $\mathrm{R}$ & $\mathrm{Sp}$ \\
\hline $\mathrm{CI}$ & 5.0 & 4.6 & 6.6 & 5.5 & 5.4 & 6.0 & 4.5 & 5.1 & 6.5 & 5.6 & 5.6 & 5.4 \\
& 1.7 & 1.9 & 1.8 & 2.7 & 1.5 & 1.9 & 1.3 & 2.1 & 2.0 & 1.7 & 1.7 & 2.1 \\
\hline $\mathrm{G}$ & 5.3 & 5.9 & 3.2 & 3.4 & 3.3 & 4.0 & 2.8 & 3.7 & 3.1 & 5.4 & 3.5 & 4.1 \\
$\mathrm{M}$ & 2.5 & 2.6 & 2.0 & 2.5 & 1.6 & 2.3 & 1.7 & 2.5 & 1.7 & 2.7 & 1.9 & 2.4 \\
\hline $\mathrm{RV}$ & 6.1 & 5.8 & 6.7 & 6.0 & 6.8 & 5.5 & 5.8 & 5.0 & 6.7 & 5.8 & 6.4 & 5.6 \\
& 2.0 & 1.9 & 1.9 & 2.3 & 1.7 & 2.0 & 1.7 & 1.9 & 2.3 & 2.4 & 2.0 & 2.1 \\
\hline \hline
\end{tabular}

With reference to the read speech the situation is more definite, the auditory values are statistically significant $[\mathrm{F}(2.736)=102.629, \mathrm{p}=.000]$. In this case, the judgments tend to correlate slightly the lowest-pitched voice (RV) with those aspects of personality conveying confidence and dominance (average value: 6.4, SD: 2); on the contrary the highest- 
pitched voice (CI) is associated with opposite personality traits, as submissiveness (average value: 5.6, SD: 1.7). Nevertheless, by comparing $\mathrm{CI}$ and $\mathrm{RV}$, the scores relating to the adjectives lacking confidence/confident and desirous of goodwill/secure are not statistically significant. On the other hand, the judgments made by the listeners about the spontaneous speech are mostly around the medium zone of the VAS, that is 5; furthermore, in this case the differences between CI and RV are not significant $(\mathrm{p}=$ .591). Unexpectedly GM, the medium-pitched voice, gets the lowest average values, both in read 3,5 (SD: 1.9) and in spontaneous speech 4.1 (SD: 2.4), $(\mathrm{p}=0.01)$. In order to assess the correlation between judgements distribution and the VAS scores, frequency indexes were calculated and reported in a graph (see Fig. 1.).

A

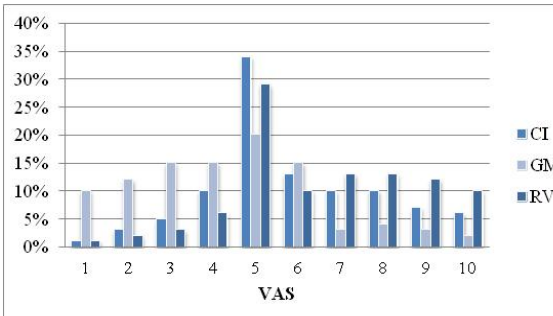

$\mathrm{B}$

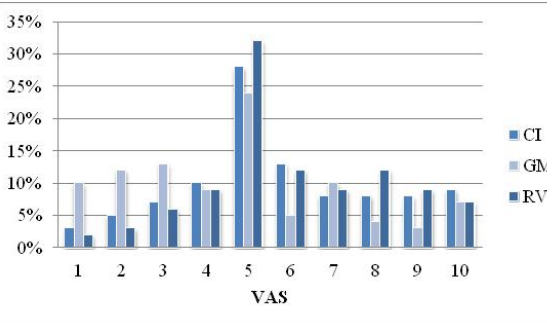

Figure 1. Percentage distribution of the perceptive judgments for read speech (A) and spontaneous speech (B)

Figure 1. (A) reveals that in read speech the distribution of values between CI and RV differs only in the left section of VAS: the 34\% (CI) and $29 \%$ (RV) of all the judgements passed on these two speakers are oriented towards the centre of the VAS. Nevertheless, the $13 \%$ of the auditory values of $\mathrm{RV}$ reaches even the right side of the VAS (7-9 points), while for $\mathrm{CI}$ this percentage drops to $10 \%$. A similar tendency is detectable also for spontaneous speech: Figure 1. (B) shows that with reference to $\mathrm{CI}$ and $\mathrm{RV}$ an important percentage of the values is oriented towards the central area of the VAS, while only the $12 \%$ for RV and the $8 \%$ for CI are placed in the right side of the VAS. A particular position is occupied by speaker GM: most of the auditory judgements is concentrated around the lowest points of the VAS, reaching a higher percentage than those achieved by the other two speakers. For read speech respectively the $12 \%$ and the $15 \%$ of the values reach the points 2 and 3 on the VAS, while for CI and RV the percentage does not exceed the $5 \%$. Furthermore, it is remarkable how the percentage of the judgments made on GM is oriented for the $10 \%$ on the score 1, on the 
contrary CI and RV show a very low percentage of judgments on this side of the VAS.

The perceptive analysis revealed that the correlation between a lowpitched voice and the perception of dominance can be considered just a tendency. In fact, this particular circumstance showed a widespread uncertainty among the listeners, who were not able to form a definite opinion about the personality traits communicated by the three female voices. It can be argued that listeners' judgements were affected by several aspects: GM was perceived as the most submissive voice among the others, even though her f0 values were medium, probably the presence of a slow speaking rate and a low intensity communicated a sense of insecurity and weakness.

This study shows that the paralinguistic meanings conveyed by human voice are not influenced only by pitch variation but also by other prosodic aspects like speech rate, pauses, intensity. In order to clarify this issue, in the future we intend to focus specifically on the interaction between these parameters and verify if there are some other variables involved in the perception of personality. In particular a further research will necessarily include the synthesis of voice for the purpose to identify precisely the aspects involved in the transmission of dominance.

\section{Notes}

1. The acoustic analysis revealed that the three voices are actually different in terms of f0. Both in read and spontaneous speech, RV presents the lowest f0 values whereas CI shows the highest ones; GM can be considered a medium-pitched voice. The other parameters that contribute to differentiate the three voices are speech rate $(\mathrm{CI}$ is the fastest one, followed by RV and GM, who is the slowest one) and intensity (RV shows the highest values, followed by CI and GM). All data are available in Gurrado, Sorianello (2017).

2. VAS is a graduated scale horizontally or vertically oriented, $100 \mathrm{~mm}$ longer, generally adopted in clinical research for analysing something that cannot be precisely measured, as pain or mood.

\section{References}

Chen, A., Gussenhoven, C., Rietveldt, T. 2004. Language specificity in perception of paralinguistic intonational meaning. Language and Speech 47(4), 311-349.

Gurrado G., Sorianello P. 2017. La percezione della dimensione di dominanza/sottomissione in un campione di voci femminili. In Bertini, C., Celata, C., Lenoci, G., Meluzzi, C., Ricci, I. (eds) 2017, Origini e funzioni della variazione fonetica. Fattori biologici e sociali a confronto, Studi AISV 3, 189-210. Milano: Officinaventuno.

Ohala, J.J. 1983. Cross-language use of pitch: an ethological view. Phonetica 40, 1-18.

Ohala, J.J. 1984. An ethological perspective on common cross-language utilization of F0 of voice. Phonetica 41, 1-16. 